\title{
El presente explica el pasado. Historias y vivencias locales en Ciudad Rodrigo (Salamanca)
}

Bajo este título pretendo hablar de las vinculaciones entre el presente y el pasado tomando como referencia el caso concreto que he estudiado, referido a una ciudad salmantina: Ciudad Rodrigo. Para ello, contemplo al menos tres aspectos: la influencia y pervivencia del pasado, el análisis del pasado y la situación en el presente.

Fue la necesidad de explicar y entender el presente lo que me llevó al pasado, ya que éste aparecía con fuerza y estaba siempre presente. Esto es algo que no creo que sea difícil de comprender para cualquiera que se haya acercado hasta este lugar, en el S-O. de la provincia de Salamanca, lo que puede ser fácil al estar en la ruta Salamanca-Portugal. Como dice un manual:

Ciudad Rodrigo se halla situada en el extremo oeste de la submeseta norte, muy cerca de Portugal, [...] a una altitud aproximada de 650-700 metros [...] Su situación es favorable a las comunicaciones N-S y NE-SO, y así queda demostrado por ser eje de las vías Dalmacia, que unía Coria con Ciudad Rodrigo y Columbiana, que unía Salamanca con Coimbra por Ciudad Rodrigo, y cuyo origen se remonta a los primeros tiempos de la dominación romana '.

Como habrán comprobado los que conocen el lugar, la historia de esta ciudad es lo primero que se ofrece a la vista al tomar contacto con ella; y lo hace con fuerza porque la grandiosidad de sus restos históricos, sus dimensiones y su belleza penetran y atraen toda la atención, como si se estuviera conociendo una ciudad de otro tiempo. Algo distinto a las ciudades a que estamos habituados hoy.

1 A. Bernal Estévez, Ciudad Rodrigo en la Edad Media. Asociación de Amigos de Ciudad Rodrigo (Salamanca, 1981), p. 103. 
Parte de ese pasado de Ciudad Rodrigo son las piedras, los monumentos, los edificios, etc. Es lo primero con lo que uno tropieza. Sin embargo, no es sólo esta imagen o aspecto exterior; también desde los primeros contactos, sus habitantes nos hablan de su historia, de ese bagaje cultural en el que entran las vicisitudes bélicas, los héroes, las hazañas, los valores y las virtudes que nos hacen ver un pasado glorioso y distinguido, mediante el que pueden y esperan despertar el interés y la admiración de los que se acercan hasta ellos.

Repetidamente nos remiten al patrimonio conservado, aconsejándonos qué hay que ver, con quién hay que hablar, dónde se encuentran documentos, libros y archivos en los que se guarda y se puede conocer todo ese pasado. Motivan al espectador a buscar lo que tanto les atrae o tratan de que atraiga a los demás, y el resultado es una historia apasionante y rica, sobre todo desde su punto de vista.

Pero además, llama la atención la presencia que todo ello tiene en la convivencia diaria. Cualquier descripción del lugar y sus costumbres se remonta a lo pretérito: en los escritos sobre la ciudad, en los pregones de sus fiestas y en los disfraces de carnaval está presente el pasado, está presente la historia. A veces incluso, actúa esta vigencia como limitación pues, al estar declarada la ciudad conjunto monumental, en cualquier remodelación o construcción han de respetarse unas determinadas normas.

La base de una historia tan abundante y agitada está probablemente en su situación geográfica: el término ha sido cruce de caminos y, como consecuencia de esto, ha dejado huella en él todo lo que transitaba por los mismos; pero además, ha estado en medio de partes opuestas entre si -unas reces, en el eje Norte-Sur; otras, en el Este-Oeste- lo que la ha convertido en el teatro y escenario donde se desarrollaban los conflictos previos, de las partes.

Ademis de ser un nudo de comunicaciones tiene su asentamiento una importante situación estratégica, defendiendo las posiciones S. y O de la provincia, de donde se desprende su notable papel histórico [...] Esta posición estratégica se desprende del entorno geográfico natural que la rodea, al estar limitada la Meseta con Portugal por la profunda hoz en que el Duero se encajona por el Norte, y por el Sistema Central por el Sur, constituyendo el lugar de paso obligado hacia Portugal, prueba de ello es que la actual red internacional de carreteras y FF.CC. sigue esa misma dirección hacia la frontera, atravesando la ciudad.

Esta posición estratégica N-S también tuvo su importancia en su día, en los tiempos de la fundación de la ciudad y su alfoz, por ser frontera con territorios de dominación árabe, y existir un puerto controlado por su jurisdicción, que atravesando el sistema montanoso, ponía en contacto las dos Mesetas, el Puerto de perales, [...] 
Al surgir con función básicamente militar, tuvo que buscar su emplazamiento sobre un cerro y ser fuertemente amurallada ${ }^{2}$.

Éstas serán las constantes que se repetirán a lo largo de su vida: ser lugar de paso de un reino a otro y punto estratégico codiciado, lo cual le ha llevado a experimentar innumerables ataques y defensas, y en esto se ha basado su sentido e importancia. Las palabras que mejor sintetizan estos momentos históricos notables son conflicto y lucha, y lo más destacado en los relatos es lógicamente su historia bélica.

En el transcurso de su historia, destacan unos momentos con más fuerza que otros, a modo de etapas en las que va perfilíndose su personalidad: éstos van desde la configuración de su nombre ${ }^{3}$, pasando por su situación estratégica y su desarrollo como ciudad y plaza militar durante la Edad Media y Moderna, hasta la Guerra de la Independencia, último momento importante de su historia bélica y el punto del que se puede partir para seguir la evolución en la que hoy está inmersa. A partir de dicha contienda antifrancesa, comienza a decaer esa misión historica de plaza militar hasta desaparecer por completo en la actualidad; y con ello, su importancia urbana.

La influencia y pervivencia del pasado se constata también en el espacio, en su estructura urbana - fiel reflejo de tiempos pretéritos-, con ese casco o ciudad amurallada - centro del lugar- y sus dos arrabales extramuros. Pero, además, el espacio no es sólo el escenario donde se desarrolla la vida, sino que esta misma se ve influenciada por aquel. La vida social tiene que acomodarse a su espacio: desde los juegos infantiles, que tienen lugar y se desarrollan entre piedras históricas, hasta su vivienda o negocio; desde las normas urbanas generales que son de aplicación a todos los lugares hasta las que, además aquí, obligan a respetar su condición de conjunto histórico-artístico. El lugar ya no es sólo patrimonio de ellos, sino también de los de fuera, que quieren conservarlo. Un espacio que nació hace tiempo y que se mantiene; que es una pervivencia del pasado y que hace a éste presente permanentemente, día a día.

Lo mismo ocurre si mencionamos las divisiones sociales relacionadas con ese espacio y las valoraciones que conllevan, casco y arrabales; o si nos preguntamos ¿quiénes vivían antes en el casco, quiénes en los arrabales, y quiénes viven hoy? o iqué ocurría dentro y fuera de las

\footnotetext{
2 BeRnAl, op. cit., pp. 103-105.

3 Ha sido llamada Miróbriga, Augustóbriga o Civitas Augusta, Ciudad del Conde Rodrigo, Ciudad de Ciudad Rodrigo, de los que hoy sólo quedan dos: Miróbriga y Ciudad Rodrigo, y a sus habitantes se les denomina mirobrigenses, gentilicio derivado de ese primitivo nombre.
} 
murallas, antes y ahora?, por señalar la segmentación más simple y evidente que se puede hacer del espacio; pero no es la única, sino que hay más.

Demográficamente la población también estuvo influenciada por los sucesos y avatares del lugar. Se despoblaban los alrededores, porque se concentraban intramuros (hambre, epidemias, mortandad). Se recuperaba, hasta que volvía a aparecer alguno de los factores de despoblación. A partir de la última contienda bélica señalada —último momento histórico importante- es cuando se inicia la recuperación demográfica final, que se estabiliza en este siglo: pudiendo decir que, en la segunda mitad de este siglo, nos encontramos con un crecimiento vegetativo estático, tendiendo al envejecimiento, que ya acusa el descenso en la tasa de natalidad.

Parece que en la repoblación definitiva de Fernando II, la ciudad creció bastante pues se conocen datos que refieren la existencia de 2 arrabales, así como que la ciudad estaba dividida en 15 colaciones o barrios. Uno de los momentos de mayor crecimiento y auge se sitúa durante el reinado de Pedro I, y uno de de sus mayores retrocesos es consecuencia del ataque de Enrique II. A mediados del siglo XV alcanza, de nuevo, un momento de máximo crecimiento ${ }^{4}$.

Económicamente, la propiedad de la tierra siempre jugó un papel importante: su base económica estuvo en el suelo y en el ganado, y aún hoy sigue siendo importante la actividad de la tierra y la ganadería. En los primeros momentos de la repoblación la necesidad de autoabastecimiento propició el desarrollo de la agricultura, y la existencia de una vega a orillas del río Águeda, el cultivo de la huerta '

También los datos sobre la existencia de dos mercados ${ }^{6}$, uno en la Plaza mayor y otro en el arrabal de San Francisco, junto con los productos que en ellos se ofrecían, indican una importante actividad comercial basada, entre otras, fundamentalmente en las actividades agrícolas y hortícolas. El mismo autor, Hernández Vegas (I:241), uno de los cronistas locales ofrece esta información que siempre es destacada por los mirobrigenses: "Doña Isabel aprovechó esta ocasión para acabar de vencer el desvío de Ciudad Rodrigo [se refiere a la solicitud tanto por parte de Isabel la Católica como de doña Juana la Beltraneja para que Ciudad Rodrigo fuera seguidora de una u otra] con el privilegio gratuito fechado

\footnotetext{
+ Bernal, op. cit.. pp. 105-108.

" BERNAL, op. cit., pp. 31-132.

- Bernal (op. cit. p. 145) toma la cita de M. HDEz. Vegas (I:212-14) quien lo extrae del libro Becerro de 1389 que ofrece información de la situación antes del cerco y destrucción de Enrique II y estado posterior de ruina en que quedó la ciudad.
} 
en Valladolid, a 31 de agosto de 1475, de celebrar un mercado franco en los martes». Confirmado por Carlos I en 1537 y por Felipe II en 1560, aún hoy sigue celebrándose este mercado los martes.

En parecidos términos podríamos hablar de los grupos sociales como el clero o la nobleza, a los que también seguimos encontrando hoy como tales grupos significativamente importantes. De la actividad religiosa perviven abundantes muestras físicas: no sólo tenemos numerosos edificios religiosos como la catedral o las diferentes iglesias, sino que la ciudad es sede episcopal con Obispo, Cabildo y Seminario. Y si mencionamos otras actividades tales como las Cofradías de San Antón, San Blas, San Sebastián, etc., o las Romerías y otros actos festivos parece que el punto de partida que enunciábamos al principio, "la influencia y pervivencia del pasado" queda patente.

Los primeros censos son del siglo XVI y de ellos los historiadores locales dan pocos datos al respecto, haciendo referencia principalmente a los grupos privilegiados. Lo que sí se deduce es que desde el principio el hecho de vivir en la ciudad fue un elemento de diferenciación social, y otro, pertenecer al estamento militar, cuyos miembros se sitúan en la cúspide de la estructura social. También el clero tenía prestigio social, según escriben algunos autores ${ }^{7}$.

El pasado no sólo ha conformado el lugar, sino que aún se mantiene en parte. Su dinámica natural, su evolución, se ha frenado cuando dejó de ejercer el papel que jugaba en el pasado. Baste para ello fijarnos en las instituciones dependientes de su función militar que, a lo largo de su historia, con altibajos se van consolidando hasta convertirse en plaza militar con gobernador propio durante la Guerra de la Independencia, por ejemplo. Incluso en algún momento se constituyó como provincia independiente de la de Salamanca, como nos cuenta Mateo Hernández Vegas ${ }^{8}$ :

La provincia comprendía dos Corregimientos: Salamanca y Ciudad Rodrigo; pero la capital de la provincia, declarada por Su Majestad, era Ciudad Rodrigo, y por eso residía en ella el intendente y oficinas principales de la Real Hacienda, como eran la Contaduría de Rentas, Única Contribución, Propios y Arbitrios, Administraciones generales de Rentas provinciales y Aduanas?

Bernal, op. cit., pp. 109-111.

8 Mateo HDEz. VEgAS, Ciudad Rodrigo: la catedral y la ciudad. 2 tomos. Excmo. Cabildo de la Catedral (Ciudad Rodrigo, 1982).

9 HDEZ. VEGAS, II: 281 citando El libro del Bastón que era una contestación a un Interrogatorio, dispuesto en 1769 por Orden de Carlos III, sobre Agricultura, Manufactura, Comercio, Ciencias, Noticias eclesiásticas, Policía, Salud pública e Historia Natural. 
A partir de esta línea ascendente comienza el descenso que se inicia en el siglo pasado y se continúa en el primer tercio del presente, como reflejan muy bien estas líneas extraídas de las últimas páginas de la Historia local de Mateo Hernández Vegas.

Fs verdad que Ciudad Rodrigo ha atravesado épocas mucho más críticas que la presente y que siempre ha resurgido de entre sus ruinas con nueva pujanza y energías; pero entonces se conservaban perennes las fuentes de la vida, y era cuestión de tiempo rehacerse, reorganizarse, desarrollar las fuerzas vitales momentáneamente perdidas. Hoy, secas, quizá para siempre, esas fuentes de movimiento y vida, mucho tememos que la enfermedad sea también crónica precursora de la muerte ${ }^{10}$.

No podía escribir otra cosa Hernández Vegas al contemplar cómo Ciudad Rodrigo al inicio de este siglo perdía la sede de la Audiencia de lo Criminal, de la Capitanía Militar de la Provincia y Plaza, de las Comandancias de Artillería, Ingenieros y Carabineros, así como la Caja de Reclutas e incluso la presencia militar de las escasas tropas de guarnición que aún restaban en la ciudad. Hay que imaginarse lo que esto supone para una población de unos 15.000 habitantes. Su valor como plaza fronteriza es hoy nulo, perdida la importancia militar que tuvo ya sólo le queda su diócesis.

El proceso industrial, que hubiera servido para darle la vitalidad que habia existido antes, no le ha llegado directamente más que en una pequenisima parte y con un considerable retraso; sin embargo, sí lo ha hecho indirectamente, en cuanto a aspectos negativos derivados de la industrialización, como es el hecho de haber registrado una emigración muy alta hacia otras zonas de la península donde la industrialización estaba en auge.

Con todo esto parece que el pasado debería ser una losa que tratarían de quitarse de encima, o de que fuera lo menos pesada posible. Pero, sin embargo. en la convivencia aparece con frecuencia vivificado, retornando a él. aludiendo mentalmente a él. Por tanto. uno pasa a oír "su pasado", no el que se encuentra en los manuales o tratados de historia sino el que ellos reconocen como tal.

11) HDEZ. VEciAs, II: +16 . 
Este sería el segundo aspecto: el análisis de ese pasado ${ }^{11}$. Lo que recuerdan y repiten se basa en las obras de escritores locales. Estas historias locales ${ }^{12}$ podemos decir que describen particularmente la Historia de Ciudad Rodrigo y de ellas parten los mirobrigenses para contar, hablar o recordar. Al relatar su pasado, los historiadores locales destacan unos momentos o etapas que resaltan con mayor fuerza que otros, y en ellos se detienen con más énfasis. Como característica que se repite podemos señalar dos elementos: el conflicto, la lucha. Estos son los que nutren esa historia que se cuenta, y los que pasan al recuerdo colectivo.

En estas obras encontramos que las descripciones de los acontecimientos enaltecen el lugar y a sus habitantes. Se hace en ellos mismos una selección de hechos, destacando aquellos que atañen al lugar y, sobre todo, aquellos que pueden ofrecer una imagen más positiva de la ciudad y de sus ciudadanos. Como ejemplo véase esta propuesta de uno de los autores más representativos:

escribiendo como escribimos una monografía, forzosamente hemos de pasar por alto todos aquellos sucesos que, aunque trascendentales para España, no tengan una relación directa e inmediata con Ciudad Rodrigo, al paso que nos detendremos a señalar algunos que no merecerían ciertamente los honores de la narración en una historia general ${ }^{13}$.

La historia de nuestra Catedral y de nuestra nobilísima y heroica ciudad, juntamente con pequeñas rencillas de vecindad, nos ofrecerá altos ejemplos, no superados por ningún otro pueblo y ninguna otra institución, de amor a la patria, de virtudes religiosas y cívicas, de abnegación y heroísmo, dignos de ocupar honroso lugar en las más brillantes páginas de la historia general de España [...]

¿Cómo no ofrecerla a la admiración de propios y extraños, en sus luchas en defensa de la patria, mil veces arruinada, deshecha, aniquilada, para resurgir otras tantas como el fénix de sus cenizas, y terminar viviendo, como vive en la actua-

11 Este aspecto lo hemos desarrollado más ampliamente en la comunicación titulada: "Narración histórica e identidad". J. Marcos ARÉvalo y S. Rodríguez Becerra (Coordinadores) en Antropología cultural en Extremadura. (Mérida: Publicaciones de la Asamblea de Extremadura, 1989), pp. 741-57.

12 Se conocen cuatro por el nombre de sus autores: Hernández Vegas (ya citado), Cabañas, Nogales Delicado y González Dávila. Hemos manejado las tres primeras. También, como se puede ver por las notas, el estudio de A. BERNAL sobre la Edad Media, pero éste no forma parte de ese grupo en el que se basan los mirobrigenses para conocer y recordar su pasado.

13 Dionisio DE Nogales Delicado, Historia de Ciudad Rodrigo. (Salamanca: Asoc. Amigos de Ciudad Rodrigo, 1982, 1. ${ }^{\text {a }}$ ed.). Con prólogo del que era Alcalde: Miguel Cid Cebrián. 
lidad, no de otra suerte que el soldado estropeado en la guerra, entre el temor y la esperanza, entre la vida y la muerte? ${ }^{14}$.

Acerca de estas historias locales nos basta con exponer la opinión del historiador A. Bernal, manifestada en la Introducción de su obra, para ofrecer una mejor información acerca de las fuentes donde los mirobrigenses encuentran que está escrito su pasado: "Las historias tradicionales [se refiere a las que llamamos historias locales] de la ciudad... quienes las escribieran [...] románticos enamorados de su patria chica, que tratan de glosar sus hazañas en un ambiente triunfalista, [...], el carácter teológico y providencialista que la preside [...]" y de "[...] la "Historia de la Muy Noble y Muy Leal Ciudad de Ciudad Rodrigo" - de Nogales Delicado- $[$ [...] título muy pomposo, que ya nos pone en cierto modo sobre aviso de su contenido [...] sólo atiende a hechos políticos y militares de relieve, en ocasiones desconectados de la realidad histórica castellana [...]", para concluir diciendo de M. Hdez. Vegas que: "... También es muy partidista, emitiendo graves juicios de valor, denominando por ejemplo a Enrique II en tono despectivo bastardo y fratricida, dejándose llevar siempre por las líneas legitimistas de la monarquía. Es también una historia descriptiva, que se limita a narrar sucesos, guerras, idas y venidas, con evidente desconexión de la realidad histórica del momento, y además, triunfalista..." reconociendo, a pesar de estas opiniones, que "los datos que aportan, en ocasiones resultan muy valiosos ${ }^{15}$.

El recuerdo colectivo se basa en estas obras de autores locales, y a ellos acuden cuando se hace mención de la historia, cuando se quiere demostrar un importante pasado....De esta historia "que se cuenta", que constituye ese recuerdo colectivo, destacaríamos como claves de la misma los siguientes elementos, momentos y hechos:

a) El nombre y el escudo de la ciudad: se trata de los símbolos de la ciudad, no de los habitantes. El carácter que tienen ambos -el nombre y el escudo- de lejanos, antiguos, remotos e importantes, lo han transmitido a la ciudad.

De todos los nombres con que ha sido designada, el que se considera primero y más antiguo es el de Miróbriga, y junto con el de Ciudad Rodrigo son los que tienen vigencia en el presente. A la entrada de la ciudad se encuentra un monumento que consta de tres columnas colocadas en ángulo; anteriormente tuvieron otros emplazamientos: el arrabal de San Francisco, la Plaza mayor. Estas tres columnas son las mismas que

\footnotetext{
${ }^{14}$ HDEz. VEGas, I: prólogo, I-III.

15 Bernal, A., op. cit., pp. 9-13.
} 
configuran el escudo de la ciudad según los historiadores. De ambas cosas nos hablan estas citas: del nombre de Miróbriga ${ }^{16} \mathrm{y}$ de las tres columnas, ${ }^{17}$ que para unos historiadores señalan límites entre provincias a modo de mojones y para otros son columnas monumentales, pero en cualquier caso de origen romano.

b) El siglo XIV: en él se ubican una serie de héroes, personajes, hechos o leyendas que, con la deformación sufrida, pasan a formar parte de narraciones desconectadas casi con la historia. Nogales Delicado cuenta con concisión y claridad todos los sucesos y leyendas ya famosas, como las de D. ${ }^{2}$ María de Adam, el obispo resucitado, La Coronada, Lorenza Iglesias, el ciego Sabino, etc.; las rivalidades familiares de los García López y los Pacheco y las biografías de todos los mirobrigenses ilustres ${ }^{18}$.

El capítulo XXV del Tomo I de Hdez. Vegas, lo titula "Época novelesca de la bistoria de Ciudad Rodrigo.. Y comienza así:

El siglo XIV es la época que pudiéramos llamar heroica y caballeresca de la historia de nuestra ciudad. Durante él se desarrollan todos los acontecimientos extraordinarios que en forma de leyenda han llegado hasta nosotros, y que, penetrando en la entraña del pueblo, tanto han contribuido a excitar la fantasía, educar el corazón y formar el carácter de los mirobrigenses ${ }^{1}$.

c) La Guerra de la Independencia: es el último acontecimiento histórico importante para "su pasado" y, al mismo tiempo, el más próximo al presente y, por tanto, del que conservan mayor número de recuerdos físicos, menciones, etc. Esto hace que sea mayor el número de personas que tienen alguna idea acerca de este momento. Por tanto, la frecuencia del mismo en la actualidad es más abundante y efectiva, llegando en algunos casos a preferirlo a los tiempos presentes.

Con gusto nos sumaríamos ahora en los recuerdos de aquellos días de gloria, tan diferentes de los nuestros, que no dan de sí más que ruindad, y pequeñez, y miserias. Con delectación evocaríamos una por una todas aquellas legendarias hazañas, siquiera para refrescar nuestra memoria con el recuerdo de algo grande, honrado y noble; reanimar nuestro abatido espíritu con el fuego sagrado de aquellas grandiosas epopeyas, hoy casi increibles; avivar, en nuestro pecho, la llama santa de amor patrio que ardía en el de nuestros heroicos padres... ${ }^{20}$.

16 Nogales Delicado, op. cit., p. 25.

17 Nogales Delicado, op. cit., p 33.

18 Nogales Delicado, op. cit. En el Prólogo de Miguel Cid.

19 HDEZ. VEGAS, op. cit., I:185.

20 HDEZ. Vegas, II:324. 


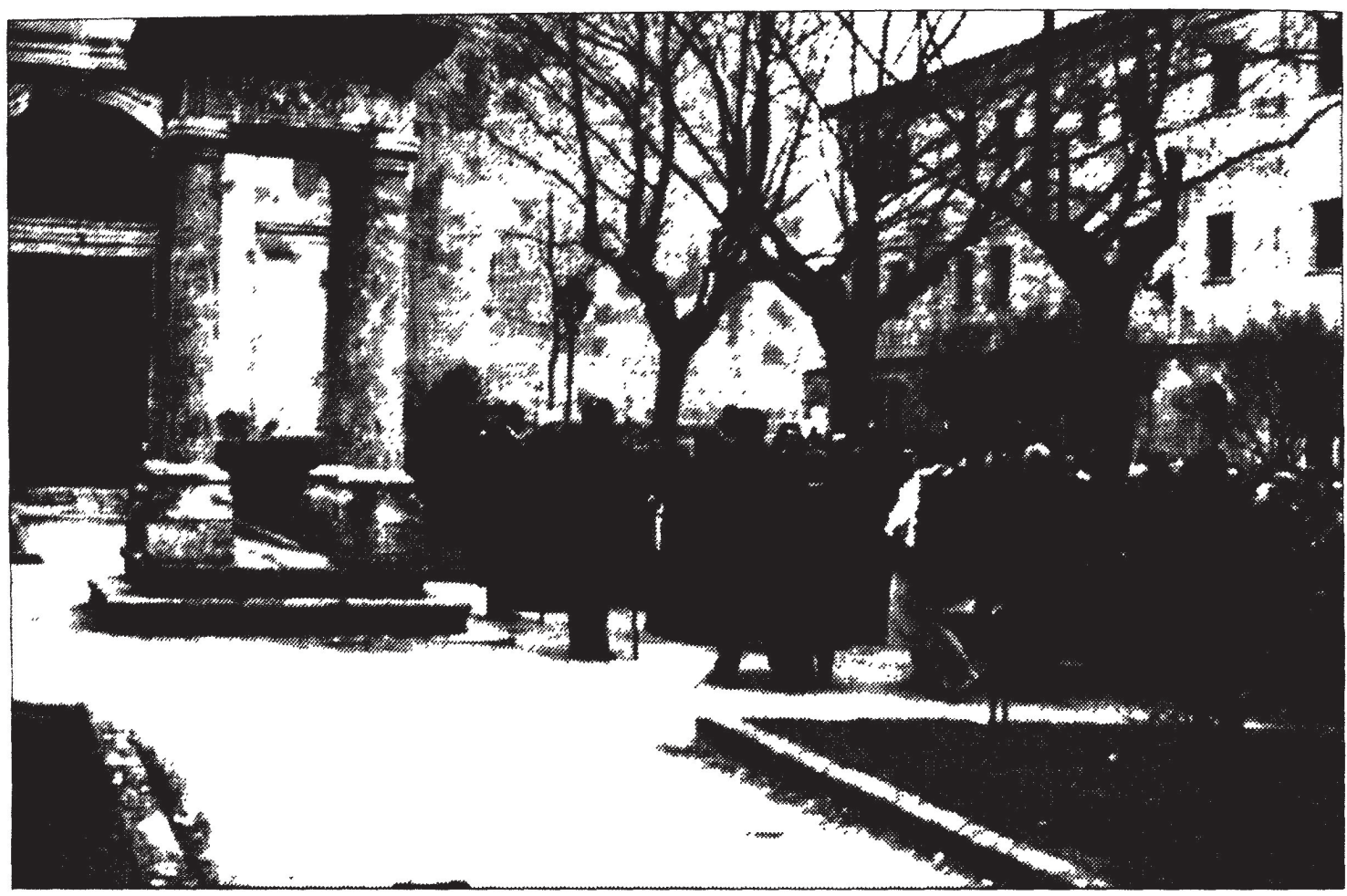

Fis, 1.-Monumento a Herrasti, héroe de la Guerra de Independencia. Responso por su alma el día de San Sebastián.

Las descripciones de este último acontecimiento de su historia incluyen tanto héroes como eventos colectivos, pero debe destacarse el provecho presente que se saca de la resistencia popular a la invasión francesa, apoyada en la caballería inglesa.

Cáusanos maravilla y orgullo a la vez la extraordinaria magnitud de los medios que emplearon los franceses para apoderarse de lo que, con hipócrito desdén, llamaban una bicoca. !Nada menos que tres mariscales, diez generales, veintiocho brigalderes, setenta mil soldados, doscientos canones y cinco meses de asedio necesitaron para lencer a un punado de valientes que peleaba tras de unas viejas tapias! "2 |... Formalizóse el sitio el 8 de Enero de 1812, siguiendo los ingleses paso a paso el mismo plan desarrollado por los franceses; pero éstos no supieron defender más de diez dias la plaza cuya conquista les había costado a ellos tres meses: $=$

Mezclan en su recuerdo del becho bistórico tanto "la bistoria" como la fantasia. Hay una tergiversación hacia la leyenda, hacia la narración apologética: pero ahora, en este momento histórico cercano se evidencia aún más. Y todo ello, teniendo como eje -que genera y da lugar a esa

\footnotetext{
2 No(iALE DELICAD) (), p. 132.

$\therefore$ HDEZ VECIAS, II:3+8.
} 
apología - la violencia, el conflicto y la lucha contra un enemigo extranjero que atraviesa el país.. La constante más pertinaz de su recuerdo histórico.

A la Guerra de la Independencia, más que a ningún otro momento, acuden a nutrirse para evocaciones actuales del pasado; y el tiempo presente en que más se concreta esta evocación (o lo que es lo mismo, la reinterpretación) es en la fiesta del Carnaval, tanto en soportes escritos (periódicos, números monográficos, programas de la fiesta, discursos, pregones, etc.) como en disfraces o representaciones.

Curiosamente, lo que consideran el final irrecuperable de un pasado determinado y peculiar es, a la vez, lo que les sirve de fuente eficaz y abundante para sintetizar o evocar ese pasado. Evocación que presenta dos características:

a) Las figuras y los personajes se convierten en héroes, engrandecidos popularmente por los valores peculiares y románticos que les adjudican (como audaz, guerrero, violento, sangriento, noble, leal y fiel, entre otros).

b) Los bechos históricos se convierten en levendas, al desdibujarlos y exagerarlos para demostrar la importancia del lugar y de sus habitantes en ese pasado que de alguna manera, a su vez, pervive hoy. Importancia que se apoya en la grandiosidad de esos hechos, tanto como en tener ese pasado determinado.

Así pues, lo que compone esta historia oral son tanto los recuerdos de la otra historia local como las imágenes fantásticas que quedan, después de seleccionar las partes y sintetizar un nuevo conjunto de esa historia. Recuerdos e imágenes dadas por los eruditos locales, que son la bistoria imaginada de su pasado. Un pasado que les legitima como grupo, con esas características por herencia directa.

Como resumen de todos los fenómenos anteriores (selección, reinterpretación, modificación, recuerdos) nos podemos centrar en esa imagen que recoge o sintetiza su pasado. En esa imagen final que ofrecen hoy manifiestan su conexión con el presente y, también, su antagonismo. Para ellos representan la cara y cruz de la misma moneda; para los demás, una diferenciación por la peculiaridad y originalidad puesta de manifiesto en actos públicos y colectivos como los que se centran prioritariamente en torno del Carnaval. Es la gran fiesta, que les diferencia y a la vez les confirma y halaga.

La fiesta de carnaval es motivo de orgullo para todo mirobrigense. Ni siquiera dejó de celebrarse durante el franquismo, aunque sufrió algunas modificaciones como, por ejemplo: denominarse con otro nombre (Fiestas tradicionales), o suprimir de sus actos los bailes de disfraces con máscara o antifaz; sin embargo, el resto de los actos se mantuvieron. Los actos más repetitivos y destacados son los 
encierros y desencierros de toros. Durante los cuatro días que celebran el carnaval se repite este programa: encierro, capea; desencierro por la mañana; corrida, capea y desencierro por la tarde. La participación de los mirobrigenses en todos ellos, excepto en las corridas, es algo singular por la valoración que de ello hacen, por la importancia que le conceden, por el orgullo colectivo que tienen de sus actos taurinos. Además tienen sus disfraces, tanto por la calle como en los distintos lugares donde se celebran los bailes, pregón, etc. ${ }^{23}$.

Esta imagen tiene que ver primeramente con el lugar - la ciudadcomo algo permanente y estable a lo largo de los tiempos; definen primero la ciudad y luego su transcurso, trazado por sus ascendientes. Todo ello pasa al presente, que lo mantiene como una línea de continuidad sin ruptura, aunque con modificaciones en las que no han intervenido directamente sino que les vienen de fuera. Se les imponen de nuevo y tratan de subsumirlos en una sombra o letargo, al que se enfrentan con sus recuerdos, reclamando su parte de importancia actual en herencia de la que tuvieron antes. Véase una muestra de un texto "de actualidad", recogido de uno de sus historiadores locales:

Muchos fundan grandes esperanzas en que el Pantano del Águeda sea un manantial de riqueza y prosperidad para Ciudad Rodrigo [...] Ojalá sea así, pues, al fin, nosotros deseamos para nuestro pueblo el bienestar en todos los órdenes, pero, aunque así fuera, los enamorados del Ciudad Rodrigo histórico y glorioso, sentiriamos siempre la nostalgia del pasado, pues, por muy optimistas que queramos ser y mucho que queramos soñar, siempre serán muy distintas la condición, la fisonomía, la significación histórica y la categoría social de una ciudad noble, heroica, gloriosa y las de un pueblo, por rico y próspero que sea, de chalanes, exportadores de judías y fabricantes de conservas de tomates y pimientos morrones ${ }^{2 t}$.

Esta imagen se puede concretar en el lema de antigua, noble $y$ leal que adorna el escudo de la ciudad, y que sintetiza la importancia adquirida por el papel desempeñado en los acontecimientos, por su protagonismo decisivo en los hechos en los que los actores - sus antepasados- eran valientes, audaces, vencedores, fieles, etc., y los hechos, asombrosos, heroicos, legendarios. Sus antecesores eran todo lo dicho, como piensan seguir ellos mismos siéndolo en la actualidad, y el mejor paralelo que encuentran para demostrarlo es en su fiesta del Carnaval, donde se presentan - mejor dicho, se "representan»-audaces, valientes, vencedores en

23. Este aspecto ha sido desarrollado por la autora en otro artículo: «El Toro y la Fiestan, en Luis DIAz (Coord.), Aproximación antropológica a Castilla y León. (Barcelona: Anthropos, 1988), pp. 167-90.

24 HDEZ. VEGAS, II:417-18. 
sus actuaciones frente a los animales (los toros), y fieles con su tradición, con lo suyo que se continúa, leales a esa herencia. Con todo ello pretenden, además, despertar admiración. La importancia de ayer se opone al letargo y olvido de hoy, resultando el presente como antagonismo de sí mismos.

\section{III}

Hemos puesto de manifiesto cómo se va haciendo una selección paulatina y progresiva para llegar, quizás, a un estereotipo, a una imagen sintética que aglutine el recuerdo global y colectivo de su interpretación del pasado y, a la vez, les defina e identifique hoy, mencionando el momento ritual en que esto es más claro y patente.

Pero acerca de este proceso selectivo hay también algo que decir. De alguna manera perciben que, en el proceso real de la vida de una sociedad, cualquier momento es fruto y resultado de los momentos anteriores, en mayor o menor medida. Las raíces reales del presente están en el pasado; de ahí que mirando a ese pasado, su situación actual se comprenda mejor. Por eso quieren también, a su manera, dominar el pasado para que cumpla esa función presente.

Con los relatos de esta historia epopéyica y apasionante, de hazañas y aventuras novelescas, lo que quieren ante todo es despertar admiración a los asistentes y a sí mismos. Las palabras que mejor pueden sintetizar todos esos momentos destacados y que seleccionan de su historia, son: conflicto, lucha, guerra..., de las que siempre han de salir victoriosos, vencedores, engrandecidos. Los héroes y los hechos que gozan de mayor popularidad son los que han adquirido esas características en enfrentamientos con los enemigos de la ciudad, con los ajenos, más que los que se enfrentan entre sí, con sus iguales de la ciudad; con otros antepasados. Hacen hincapié en el interés que los poderes externos tuvieron en y por la ciudad concediéndoles privilegios, demostrando con ello la importancia que la ciudad y sus habitantes tenían para esos poderes. De ahí que destaquen ese protagonismo externo:

De la importancia que la ciudad reviste a ojos de los monarcas, ya sea por su lealtad política, por su posición estratégica, por causas diplomáticas, sirva de baremo el hecho de que desde 1312 a 1454, vinieron a Ciudad Rodrigo por unos u otras razones, 5 de los 6 reyes que gobernaron Castilla en ese período, y sólo Enrique III no consta que viniera. Tampoco consta que viniera Enrique IV, ni como rey, ni siendo como fue señor de la ciudad, aunque sí tuvo frecuentes atenciones con ella, como fue la confirmación en 1454 de todos los 
privilegios, exenciones y libertades del obispo y cabildo, dado en Arévalo a 21 de diciembre ${ }^{25}$.

Esta selección, pues, se caracteriza por particularizar determinados aspectos parciales de la historia general del país, por destacar lo que da prestigio, que se basa en sus conocidos hombres valientes-ganadores, y en ser un lugar antiguo e importante. Así, las etapas destacadas, las que son tratadas con mayor énfasis, vienen a legitimar el título de la ciudad de "Antigua, Noble y Leal".

la vida de Ciudad Rodrigo, está tan ligada en la Edad Media y parte de la Moderna a los acontecimientos nacionales, que es fácil seguir la historia de España y sus reinos a través de la de Nogales.

Ello, tanto llama la atención al foráneo como llena de orgullo a los mirobrigenses y demuestra además la importancia que tuvo nuestra ciudad que no se corresponde ni mucho menos con la actual, si exceptuamos, por imperecedero, el tesoro arquitectónico que atesora ${ }^{26}$.

La gran gesta-epopeya, que es la Guerra de la Independencia, supone en realidad a la vez el fin de la historia de la "antigua, noble y leal" ciudad. Las tres cualidades siguen teniendo vigencia en la actualidad. Es evidente que es antigua; que como grupo posee nobleza, y que defiende y hace alardes de lealtad.

La decadencia de la función histórica como plaza militar (hasta desaparecer por completo en la actualidad, y con ello, la importancia de la ciudad) sin ser sustituida por otros objetivos que revitalizasen su imagen fuera, y de manera relevante dentro del contexto al que pertenece, hace que el pasado sea lo importante; y que, a veces, traten de refugiarse en él buscando la gloria de antes. Así pues, ese pasado está sustituyendo su presente.

Ésta es, muy a grandes rasgos desde su perspectiva, la visión de "su historia contada por ellos mismos. Pues bien, lo que nos proponemos finalmente es ver las vinculaciones internas que creemos se establecen en función determinante, no del pasado, sino del presente. Es decir, de qué forma el presente condiciona una visión del pasado. Creemos que la situación actual exige una mirada al pasado, provoca volver a él; pero en esa vuelta se trata de buscar también algo específico.

\footnotetext{
25 Bernal, A., op. cit., pp. 53-54.

26 Nogales Delicado, op. cit., Prólogo.
} 
Hemos hablado del pasado, de su interpretación y del proceso que da lugar al recuerdo colectivo, es decir, de la memoria colectiva. Intentaremos ahora hablar del papel que juega el presente, y para ello tendremos en cuenta especialmente algunos factores:

1. El papel de la ciudad y de sus habitantes como plaza fronteriza, y la ausencia actual de esa función.

2. El contexto regional en el que está ubicada hoy. Es la zona deprimida de la frontera portuguesa, región marginada de la actividad económica nacional, que se centra en otras zonas.

3. Sigue siendo una ciudad fronteriza en un mundo que camina hacia un futuro sin fronteras.

Su situación actual es poco halagüeña. En el presente Ciudad Rodrigo no es un lugar importante. Puede pensarse que es un lugar turístico, un poco apartado de los circuitos; en realidad es algo que los turistas encuentran en su camino, de paso, pero que no exige permanencia en él.

Sus fiestas de Carnaval tienen una repercusión limitada al espacio próximo comarcal y provincial. Es decir, que tampoco consiguen ser importantes más allá de sus proximidades.

Respecto a los servicios (sanidad, educación, comercio, etc.) que antes centralizaba, la facilidad de las comunicaciones actualmente está haciendo

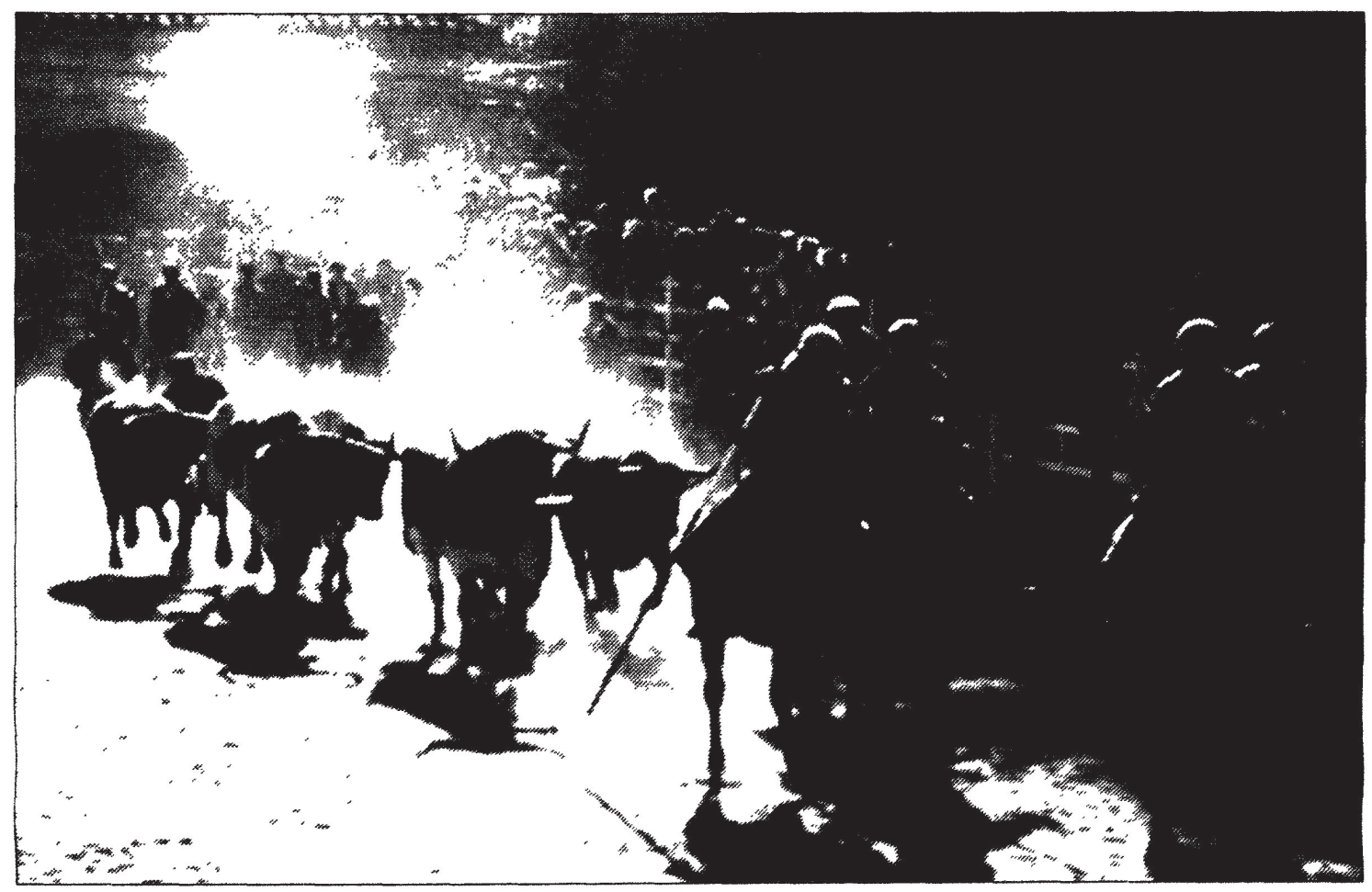

Fig. 2.-Escena de Carnaval: encierro con caballos. 
que su importancia sea desplazada hacia Salamanca, que a sólo $80 \mathrm{kms}$. ofrece mayores atractivos.

Por tanto, hoy podemos concentrar su importancia urbana casi solamente en su riqueza monumental. Sus fiestas y los servicios que ofrece tienen también un radio de influencia reducido a sus proximidades, e incluso, estos últimos en retroceso. Para los cercanos o próximos, los de su entorno geográfico, su importancia urbana real queda reducida a aspectos muy puntuales. Ante esto se consuelan con una interpretación de la historia configurando imágenes, símbolos y modelos que expresan o quieren actualizar en carnavales, con los alardes que hacen y el prestigio que quieren merecer y recibir de los espectadores.

Cuando el presente no es halagüeño ni favorable, y el futuro previsible no parece que vaya a modificar esta imagen, la mirada hacia atrás se hace necesaria. Si el pasado se presta a ofrecer una imagen más positiva que el presente y el futuro, entonces es necesario y se convierte en elemento de satisfacción y fuente de orgullo colectivos.

Por todo esto recurren al pasado, a su historia, cuando piensan en sí mismos, y lo expresan también en escritos laudatorios sobre la ciudad y sus fiestas. Piensan que tienen algo que los demás no tienen: esa historia gloriosa de la que son testigos las piedras actuales. En cambio, se enfrentan a un presente en el que su vida está aletargada, y a un futuro que es sombrio. Ahora se trata de un lugar perdido, alejado de lo que hoy puede ser importante; y su función actual, su importancia, se reduce a su espacio de alrededor, a su entorno próximo.

Para completar la descripción negativa que hacemos del presente extraemos algunos datos de un trabajo realizado entre enero y marzo de 1988 por EDIS, S.A. (Equipo de Investigaciones Sociológicas, S.A.) bajo el título de: "Necesidades y carencias básicas en Ciudad Rodrigo". Ya en la Presentación se dice:

El principal problema de Ciudad Rodrigo actual y la base y raíz de todos los demás es la baja tasa de actividad y el elevado índice de paro de su población potencialmente productiva. El que sólo 1 de cada 5 mirobrigenses trabaje de forma estable, sitúa la población en niveles medios de pobreza y falta de recursos, peligrosos y conflictivos.

Para más adelante, en las páginas 25 a 27, ofrecernos los siguientes datos igualmente deprimentes:

Existen 1.124 analfabetos (entre absolutos y relativos) o lo que es lo mismo el $9,9 \%$ de la población mayor de 18 años están afectados por este problema [...] La tasa de paro es del $26,35 \%$. Si a esto se añade la tasa de subempleo, $8,6 \%$, ten- 
dremos un total de parados más subempleados del 34,9\% [...] La tasa desde cualquier punto de vista es altísima. Los parados jóvenes (18-24 años) supone un 34,7\% de los jóvenes [...] Los trabajadores en activo son unos 3.485 que suponen un $30,7 \%$ sobre la población mayor de 18 años y un $22,4 \%$ sobre el total de la población. La tasa de empleo, la media nacional, es aproximadamente del 33$35 \%$ [...] La población pasiva se eleva a 12.070 personas (la población de hecho en 1986 era de 15.555) entre niños, parados, subempleados, amas de casa, enfermos y jubilados $8 \ldots 9$ La renta "per cápitav/mes está entre 32.000 y 35.000 ptas./ ind./mes. Casi un tercio por debajo de la media nacional [...] Un 40,4\% del total de la población de Ciudad Rodrigo viviría, con criterios de la CEE, en pobreza con relación a España.

Otro trabajo más reciente, de 1994, realizado por el mismo equipo EDIS, confirma esta misma situación de declive ${ }^{27}$. Creo que estos datos son suficientes para darnos una imagen de cuál es la realidad actual. Uniendo esto a lo mencionado respecto a su importancia urbana decreciente hoy, parece confirmado lo que ya hemos apuntado: tiene un presente y un futuro poco esperanzador. Por eso, frente a esta situación presente tan desfavorable $y$ en declive el pasado puede compensar por antagonismo. Todo ello configura la imagen propia que ahora les gustaría tener del lugar, de su importancia, de su riqueza, de su prestigio y de su protagonismo.

En el futuro no se vislumbran cambios sugerentes que permitan pensar en renacimientos o revitalizaciones. Antes bien, casi las pocas iniciativas que surgen, al poco quedan ahogadas, sin posibilidad de seguir, de perdurar o crecer. En este contexto la situación puede explicar el recurso romántico "al recuerdo colectivo del pasado" y a la selección e interpretación favorable dentro de un presente de añoranza.

Si actualmente subsisten, y lo que los de fuera valoran son sus restos históricos, parece lógico que se aferren a lo que les queda de importancia, según la opinión externa autorizada, y que lo reactualicen.

Necesitan el pasado no sólo para para sentirse orgullosos y para saberse importantes sino para reconocerse e identificarse ante el mundo exterior. Por lo mismo que necesitan reinterpretarlo, para ofrecerlo a los ojos de los de fuera según la imagen que creen que los demás puedan aceptar de ellos mismos.

¿Es únicamente la situación actual la que motiva a utilizar la historia con una interpretación determinada? Se trata desde luego de una interpretación que compensa la visión actual, en la que se proyecta aquello que no se tiene y se desea tener y que ellos reclaman, pero que se debe

${ }^{27}$ EDIS, Las condiciones de vida de la población pobre de la provincia de Salamanca. Fundación FOESSA. Madrid, 1994. 
otorgar por los de fuera, a quienes lo que les atrae es la riqueza artística y las fiestas, lo único que pueden valorar. El futuro no se presenta agradable, ni parece que se pueda modificar la situación actual; lo que tienen importante es sólo el pasado.

Para ellos Ciudad Rodrigo sigue siendo un lugar de pasado antiguo y noble. Hay nobleza de títulos (cuentan entre los propietarios de palacios a los Condes de Montarco, al Marqués de los Altares,...) pero también nobleza de corazón, que manifiestan en otro gentilicio: "farinatos" con el que se denominan, además del de mirobrigenses. El "farinato" es el natural del lugar -o, a veces, el adoptivo- amante, defensor y participante de sus peculiaridades tradicionales. Los farinatos, según ellos, son gente noble -como los buenos toros-y leales para con su pueblo. Su "farinatismo" es eso: la defensa a ultranza de Ciudad Rodrigo, de su herencia y de sus peculiaridades actuales. Quizás la frase de identificación que mejor lo resume sea la que ellos mismos reiteran: "No bay otra ciudad, otro pueblo como éste." A la que podríamos añadir, como información implícita a dicha frase: "con esa historia, con sus carnavales y con sus tradiciones". Que son los pilares que les quedan, de satisfacción y orgullo colectivo.

\section{CARIDAD HERNÁNDEZ SÁNCHEZ}

Universidad Complutense de Madrid

Lat historia sirve al presente de diferentes maneras. Las sociedades miran al pasado con diversos objetivos, pero para poder alcanzarlos necesitan siempre su reinterpretación. ¿Qué objetivos tienen cuando vuelven su mirada hacia atrás? ¿Por qué esos objetivos? ¿Cómo reinterpretan la historia para cumplirlos? Estas son las preguntas que hemos intentado responder en nuestro trabajo. Cuando el presente no es halagüeño, ni favorable, y el futuro previsible no parece que vaya a modificar esta imagen, la mirada al pasado se hace necesaria. Si ofrece una imagen más positiva que el presente y el futuro, entonces ese pasado es necesario y se convierte en elemento de satisfacción y fuente de orgullo colectivos.

History serves the present in different ways. Every society contemplates with different objectives its own past, which is necessarily reinterpreted to fit that purpose. Which are the objectives of this reconsideration of the past? Why those objectives? How to reinterpret history to seek them? This paper aims at answering these questions. When the present is not gratifying nor pleasing, and the coming future does not seem to be able to change that trend, reconsidering the past becomes necessary. If the past gives an image that is more positive than the present and the future, then it becomes a basic element of collective satisfaction and pride. 